\title{
Kesiapan Masyarakat dalam Melaksanakan dan Memanfaatkan Posyandu Penyakit Tidak Menular di Desa Cilayung dan Cipacing, Kecamatan Jatinangor
}

\author{
Yulia Sofiatin, ${ }^{1}$ Rully M.A. Roesli ${ }^{2}$ \\ ${ }^{1}$ Departemen Ilmu Kesehatan Masyarakat, Fakultas Kedokteran, Universitas Padjadjaran, Bandung, \\ ${ }^{2}$ Departemen Ilmu Penyakit Dalam, Fakultas Kedokteran, Universitas Padjadjaran/ \\ RSUP Dr. Hasan Sadikin, Bandung
}

\begin{abstract}
Abstrak
Pengendalian hipertensi dan penyakit tidak menular (PTM) memerlukan kerja sama pasien karena pilar utama pengendalian PTM adalah pengetahuan penderita dan kepatuhan dalam menjalankan upaya pengendaliannya. Sampai saat ini pemberian edukasi di sarana kesehatan tidak efektif sehingga diperlukan upaya lain seperti kelompok dukungan pasien dan peningkatan kemampuan masyarakat. Pos pelayanan terpadu (posyandu) PTM merupakan salah satu alternatif. Penelitian ini bertujuan menggali kesiapan kader posyandu dan pasien hipertensi mengenai kemungkinan pelaksanaan posyandu khusus PTM. Telah dilakukan diskusi kelompok terarah (DKT) terhadap dua kelompok (kader dan penderita) di Desa Cilayung dan Cipacing serta 1 (satu) sesi wawancara mendalam terhadap Kepala Puskesmas Kecamatan Jatinangor, Sumedang pada Maret-April 2017 dengan tingkat partisipasi peserta cukup baik. Keempat kelompok menyatakan kebutuhan terhadap posyandu PTM dengan aktivitas selain pemantauan tekanan darah dan berat badan yang dibutuhkan adalah penyuluhan mengenai perbaikan gaya hidup dan kepatuhan berobat. Kader Desa Cipacing siap melaksanakan penyuluhan jika telah mendapat pelatihan, tetapi kader Desa Cilayung menginginkan penyuluh dari luar lingkungan mereka. Terdapat kebutuhan kemudahan mendapatkan obat karena pengambilan obat di puskesmas dirasakan membutuhkan biaya transportasi yang cukup tinggi. Dapat disimpulkan bahwa masyarakat dan kader merasakan kebutuhan terhadap posyandu PTM, tetapi kesiapan mereka berbeda-beda.
\end{abstract}

Kata kunci: Kelompok dukungan, kesiapan masyarakat, posyandu penyakit tidak menular

\section{Community Readiness to Run and Utilize Integrated Health Post for Non-Communicable Disease in Cilayung and Cipacing Villages, Jatinangor}

\begin{abstract}
The main pilars of non-communicable diseases (NCDs) management are patient's awareness, knowledge and compliance. At present, education by health provider in health facilities has been proven to be not effective that other measures such as patient support group and community empowerement are needed. The options is through integrated health post (posyandu) for NCD. The aim of this research was to explore the readiness of the community to run and utilize such post. Four sessions of focus group discussions with two groups of health cadres and two groups of people with high blood pressure in Cilayung and Cipacing villages and 1 (one) session of indepth interview towards the Head of Public Health Center (Puskesmas) at Jatinangor, Sumedang, Indonesia were held on MarchApril 2017 with high participations. Each group expresses the needs of patient support group and community empowerement through regular integrated health post for NCDs. Schedulled screening and mass education especially for life style modification and drug used are urgent. Health cadres of urban community are ready to lead the activities, while those from rural area ask for formal educators. Drug dispensing at public health center is favourable due to expensive transportation to primary health care. In conclusion, communities in Jatinangor need integrated health post for NCD to assist them to manage their blood pressure and other NCDs although their readinesses were vary.
\end{abstract}

Key words: Community readiness, integrated health post for NCDs, support group

Korespondensi: Yulia Sofiatin. Departemen Ilmu Kesehatan Masyarakat, Fakultas Kedokteran, Universitas Padjadjaran. Jln. Prof. Eijkman No. 38, Bandung, Jawa Barat, Indonesia. HP: +628122325607. E-mail: y.sofiatin@unpad.ac.id 


\section{Pendahuluan}

Hipertensi merupakan penyakit yang termasuk dalam golongan yang tidak memberikan gejala dan sering kali menimbulkan komplikasi yang dapat menyebabkan kematian atau kecacatan pada penderita. ${ }^{1-3}$ Sampai saat ini keberhasilan pengendalian untuk tekanan darah dan penyakit tidak menular (PTM) lainnya di seluruh dunia sangat rendah. Kerja sama dengan penderita sangat penting karena pengobatan yang akan berlangsung seumur hidup dan harus disertai dengan perilaku hidup sehat. ${ }^{4}$ Edukasi kepada penderita dan keluarganya mengenai perbaikan gaya hidup, kepatuhan berobat, dan skrining terhadap anggota keluarganya sangat penting.4.5 Durasi pertemuan dokter dan petugas kesehatan lain dengan pasien di puskesmas sangat rendah disebabkan oleh angka kunjungan harian yang tinggi sehingga berbagai informasi yang harus diketahui penderita tidak dapat disampaikan dengan baik. ${ }^{6,7}$ Pengunjung puskesmas terbatas terhadap pasien dengan keluhan saja, sedangkan mereka yang tidak mempunyai keluhan tidak akan menyadari bila ada masalah dengan tekanan darahnya sehingga pelayanan untuk penyakit hipertensi dan PTM lainnya perlu didekatkan kepada masyarakat.

Salah satu peranan serta masyarakat dalam bidang kesehatan yang telah menunjukkan hasil adalah pos pelayanan terpadu (posyandu) untuk kesehatan ibu dan anak (KIA). Model yang serupa telah dikembangkan untuk PTM oleh Kementerian Kesehatan Republik Indonesia sejak tahun 2012. Telah tersedia Petunjuk Teknis Pos Pembinaan Terpadu Penyakit Tidak Menular serta pelatihan untuk pelatih kader pos pembinaan terpadu (posbindu) PTM sedang dieskalasi selama dua tahun ini. ${ }^{8}$ Berdasarkan atas pengamatan selama pelaksanaan survei hipertensi dan penelitian lanjutannya, posbindu penyakit tidak menular belum banyak dilaksanakan di Jatinangor. Kajian terhadap kesiapan kader posyandu dan pasien hipertensi mengenai kemungkinan pelaksanaan posyandu khusus PTM ini dilaksanakan untuk mendukung program posyandu PTM.

\section{Metode}

Penelitian ini adalah bagian penelitian dengan judul "Pencegahan Primer dan Sekunder terhadap Hipertensi pada Masyarakat Jatinangor". Dipilih metode kualitatif dengan cara pendekatan studi kasus karena dianggap tepat untuk memahami kedalaman pemahaman atas masalah posyandu PTM dari berbagai sumber. Diskusi kelompok terarah (DKT) dilaksanakan terhadap 2 (dua) kelompok informan, yaitu kader kesehatan dan juga pasien hipertensi di dua desa binaan di Jatinangor, yaitu Desa Cilayung yang bersifat perdesaan dan Desa Cipacing yang bersifat perkotaan. Keempat DKT diikuti sebanyak 8-10 informan masing-masing. Satu sesi wawancara mendalam dengan kepala puskesmas dilakukan untuk mendapat masukan lebih jauh mengenai kesiapan dukungannya dari puskesmas. Payung penelitian ini telah mendapat persetujuan etik dari Komite Etik Penelitian Kesehatan, Fakultas Kedokteran, Unpad No. 76/UN6.C.1.3.2/KEPK/ PN/2016. Penelitian dilaksanakan pada MaretApril 2017.

Kelompok informan pertama dan kedua adalah kader kesehatan yang selama ini bekerja sama dengan tim peneliti dalam melaksanakan survei awal hipertensi di Jatinangor dan telah mendapatkan pelatihan pengendalian tekanan darah. Diskusi diarahkan pada kesiapan kader dalam melaksanakan kegiatan posyandu PTM.

Kelompok informan ketiga dan juga keempat merupakan kelompok sasaran, yaitu penderita hipertensi yang sudah menjalani pemeriksaan tekanan darah pada survei awal penelitian yang dilakukan oleh Pusat Studi Kesehatan dan Kebugaran Komunitas dari Fakultas Kedokteran Unpad yang dilaksanakan periode tahun 20142015. Diskusi diarahkan terhadap kebutuhan dan kesediaan informan dalam memanfaatkan posyandu PTM.

Seluruh informan diundang untuk berkumpul di tempat yang telah ditentukan sebelumnya. Diskusi kelompok terarah pada kelompok kader dilaksanakan di sebuah rumah makan di daerah Jatinangor yang menyediakan ruang terpisah. Diskusi kelompok sasaran dilaksanakan di Balai Desa Cipacing dan rumah kader Desa Cilayung. Pedoman DKT disusun berdasar hasil penelitian sebelumnya tentang penatalaksanaan hipertensi di Balai Pengobatan Puskesmas Jatinangor dan Juknis Posbindu PTM. Setiap sesi DKT berlangsung selama 1-2 jam.

Diskusi itu dipimpin oleh peneliti sebagai moderator utama dan seorang asisten moderator mencatat serta membantu moderator menggali lebih jauh jawaban-jawaban penting. Dua orang pencatat bertanggung jawab juga terhadap alat rekaman dan mencatat jalannya diskusi. Pada diskusi ini dipergunakan istilah posyandu PTM agar informan dapat membayangkan kegiatan 
posyandu KIA sebagai referensi.

Analisis tematik dipilih dalam penelitian ini karenamerupakanmetodeyang palingtepatuntuk mengidentifikasi pola pengalaman, pandangan, dan juga persepsi dalam kelompok informan. Gambaran deskriptif didapatkan dengan cara menghitung secara objektif dan sistematis isi teks yang merupakan hasil pengumpulan data. Tujuan utama analisis ini merangkum sejumlah besar detail menjadi konsep atau gambaran yang lebih umum. Hasil DKT yang telah dibuat transkripsi dianalisis secara manual. Proses reduksi, koding, serta penentuan tema dan subtema dilakukan oleh peneliti, sedangkan transkripsi hasil DKT dilakukan oleh pencatat yang bertanggung jawab atas alat rekam.

\section{Hasil}

Desa Cipacing merupakan desa yang sejak lama mengandalkan jasa antara lain sebagai pedagang dan pegawai pabrik sebagai mata pencaharian. Lokasi desanya lebih dekat ke jalan provinsi yang menghubungkan Kota Bandung dengan Kota Tasikmalaya ataupun Kota Sumedang. Sementara itu, Desa Cilayung meskipun dalam peta tampak dekat ke jalan provinsi, tetapi aksesnya memutar dengan sebagian besar penduduknya merupakan petani (Gambar). Karakteristik informan secara umum dapat dilihat dalam Tabel 1.

Pada saat pelaksanaan diskusi dengan kader, diskusi diarahkan terhadap kesiapan informan menjalankan posyandu PTM di posyandunya masing-masing, antara lain termasuk kesiapan lokasi, waktu, dan peralatan yang dibutuhkan; kesiapan para kader untuk menjadi penyuluh;

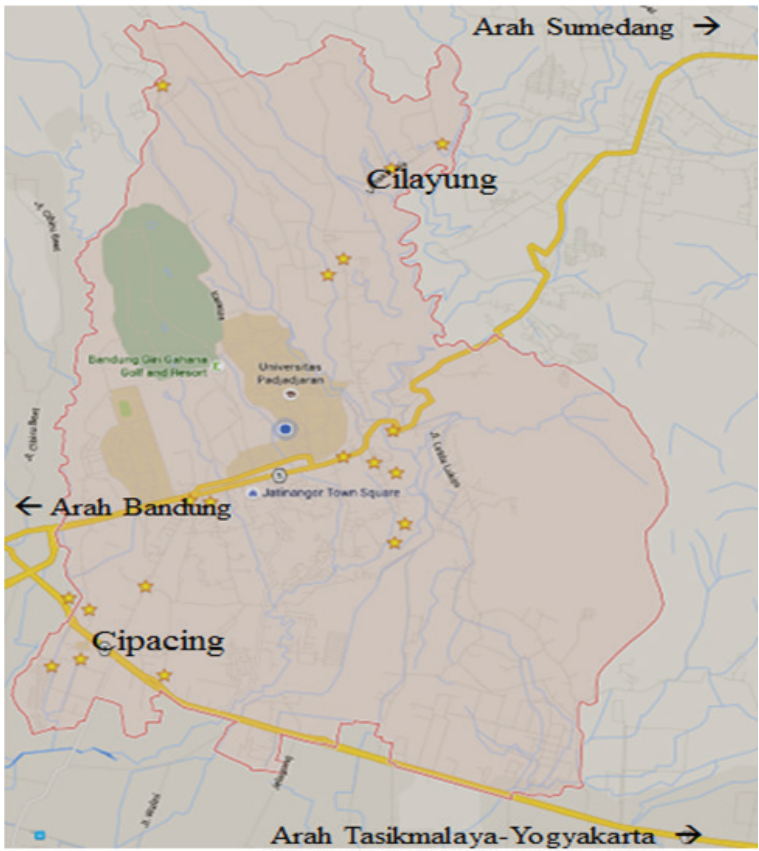

Gambar Lokasi Penelitian Desa Cipacing dan Desa Cilayung

serta kendala-kendala yang kemungkinan akan mereka hadapi. Hasil diskusi dirangkum dalam Tabel 2.

Alasan pemilihan lokasi posyandu KIA antara lain lokasi sudah dikenal, tidak ada tempat lain, dan agar peralatan yang sudah ada tidak perlu dipindahkan lagi. Sementara itu, alasan waktu yang bersamaan adalah agar tidak perlu berulang-ulang mengumumkan kegiatan kepada kelompok sasaran yang akan datang.

Para kader Desa Cipacing siap melaksanakan

Tabel 1 Karakteristik Dasar Informan

\begin{tabular}{|c|c|c|}
\hline & Desa Cilayung & Desa Cipacing \\
\hline Karakter desa & Perdesaan & Perkotaan \\
\hline \multicolumn{3}{|l|}{ Kader } \\
\hline Jumlah (orang) & 8 & 10 \\
\hline Gender & Perempuan & Perempuan \\
\hline Rentang usia (tahun) & $25-65$ & $32-50$ \\
\hline Pendidikan & SD-SMA & SMP-SMA \\
\hline Pekerjaan & $\begin{array}{l}\text { Ibu rumah tangga, berjualan makanan } \\
\text { di rumah }\end{array}$ & $\begin{array}{l}\text { Ibu rumah tangga, guru PAUD, } \\
\text { pedagang di pasar }\end{array}$ \\
\hline \multicolumn{3}{|l|}{ Kelompok sasaran } \\
\hline Jumlah (orang) & 10 & 10 \\
\hline Gender & Perempuan & Perempuan: 7 dan laki-laki: 3 \\
\hline Rentang usia (tahun) & $30-65$ & $45-68$ \\
\hline Pendidikan & SD-SMA & SD-SMA \\
\hline Pekerjaan & $\begin{array}{l}\text { Ibu rumah tangga, buruh tani, } \\
\text { berjualan di rumah }\end{array}$ & $\begin{array}{l}\text { Ibu rumah tanga, pensiunan, pengrajin, } \\
\text { pedagang di pasar, pedagang kaki lima }\end{array}$ \\
\hline
\end{tabular}


Tabel 2 Rangkuman Hasil Diskusi dengan Kader

\begin{tabular}{lll}
\hline & Desa Cilayung & Desa Cipacing \\
\hline Lokasi & Posyandu KIA, madrasah atau musala. & Posyandu KIA. \\
Waktu & Bakda salat asar. & Bersamaan dengan posyandu KIA. \\
Alat & Sebagian sudah ada. & Sebagian sudah ada. \\
Penyuluh & Tidak sanggup, sebaiknya dari puskesmas/ & Siap menjadi penyuluh, perlu pelatihan. \\
& mahasiswa. & \\
Kendala & Penyuluhan. & Menjangkau kelompok pekerja. \\
\hline
\end{tabular}

penyuluhan terkait pengendalian PTM, tetapi ingin lebih dulu mendapat pelatihan untuk setiap materi. Hambatan yang dirasakan akan dihadapi adalah menjangkau kelompok pekerja pabrik yang bekerja berdasar atas sif. Saat disampaikan kemungkinan untuk mendirikan posyandu PTM di tempat kerja maka para kader menganggapnya sebagai pilihan yang baik.

Diskusi dengan seluruh penderita hipertensi ditujukan untuk menggali kendala yang mereka hadapi saat ini untuk mengendalikan tekanan darahnya, kendala dalam menerima informasi terkait gaya hidup sehat, juga kesediaan mereka untuk memanfaatkan posyandu PTM jika sudah disediakan, dan juga harapan mereka terhadap pelayanan di posyandu PTM. Rangkuman hasil diskusi dengan kelompok sasaran dapat dilihat dalam Tabel 3.

Saat membahas kebiasaan kelompok sasaran dalam mengendalikan tekanan darah, sebagian besar informan mengaku jarang memeriksakan tekanan darahnya, tetapi beberapa orang memilih diperiksa oleh mantri atau dokter swasta, dan sebagian datang ke posyandu.

"Selama ini juga saya datang ke posyandu kalau mau periksa tensi." (C2)

Hanya dua orang informan yang berasal dari
Desa Cipacing dan satu orang dari Desa Cilayung yang secara teratur minum obat. Hampir semua informan menyatakan keberatan untuk datang setiap bulannya ke puskesmas dengan berbagai kalimat yang berbeda, pada umumnya informan menyatakan:

"Meskipun obatnya gratis (karena ikut BPJS), tapi ongkos (ke puskesmas)-nya mahal. Kalau terasa saja nanti berobat lagi." $\left(\mathrm{C}_{4}\right)$

Pada penelitian yang sebelumnya dilakukan penyuluhan mengenai pola hidup sehat yang dilaksanakan oleh mahasiswa, ternyata informan merasakan manfaatnya. Penyuluhan ini hanya diperoleh dalam kurun waktu 3 bulan dan sudah lama tidak berjalan lagi sehingga pengetahuanpengetahuan itu menjadi terlupakan. Informan yang pernah mendapatkan penyuluhan mengenai pola makan yang baik menyatakan:

"Sudah lama. Jadi sudah tidak dikerjakan lagi. Sudah lupa." (D3 dan C4)

Keempat kelompok diskusi itu menganggap bahwa pelaksanaan posyandu PTM bersamaan dengan posyandu KIA akan lebih baik. Saat disampaikan bahwa penyuluhan itu memerlukan waktu khusus, kelompok sasaran tampak berubah

Tabel 3 Rangkuman Hasil Diskusi dengan Kelompok Sasaran

\begin{tabular}{|c|c|c|}
\hline & Desa Cilayung & Desa Cipacing \\
\hline $\begin{array}{l}\text { Kendala } \\
\text { pengendalian } \\
\text { tekanan darah }\end{array}$ & $\begin{array}{l}\text { Obat tidak teratur/tidak berlanjut, } \\
\text { pengurangan asupan garam sudah lupa, } \\
\text { olahraga jalan kaki, medan curam. }\end{array}$ & $\begin{array}{l}\text { Obat tidak teratur/tidak berlanjut, } \\
\text { pengurangan asupan garam sudah lupa, } \\
\text { olahraga sambil jalan ke pasar. }\end{array}$ \\
\hline Lokasi & Posyandu KIA, madrasah atau musala. & Posyandu KIA. \\
\hline Waktu & Bakda salat asar. & Bersamaan dengan posyandu KIA. \\
\hline Olahraga & Tidak rutin, jalan kaki dari rumah ke rumah. & $\begin{array}{l}\text { Tidak rutin, ada kelompok senam, jalan } \\
\text { kaki ke pasar. }\end{array}$ \\
\hline Kegiatan & $\begin{array}{l}\text { Penyuluhan, masak bersama, penyerahan } \\
\text { obat, pemeriksaan. }\end{array}$ & $\begin{array}{l}\text { Penyuluhan, masak bersama, penyerahan } \\
\text { obat, pemeriksaan. }\end{array}$ \\
\hline
\end{tabular}


pikiran. Kelompok diskusi sasaran Desa Cilayung kemudian sepakat bahwa sore hari merupakan waktu yang tepat.

"Bakda asar, bapak-bapak sudah pulang dari sawah, sudah istirahat dan biasanya pergi ke musala. Iya, sambil menunggu salat magrib bisa tuh diadakan penyuluhan."(D4)

Kelompok sasaran Desa Cipacing masih sulit memutuskan.

"Susah Bu, kan yang kerja di pabrik sif-sifan, tidak bisa semuanya datang. Mau pagi, mau sore, pasti ada yang kerja." (C5)

Waktu diajukan kemungkinan mengadakan posyandu PTM di pabrik, ada informan yang menyatakan bahwa itu ide yang baik, tetapi sebagian besar tidak dapat memberikan masukan.

Kelompok kader Desa Cipacing tampak lebih menyukai pelaksanaan posyandu itu bersamaan dengan posyandu KIA dengan alasan harus dua kali mengumumkan dan melaksanakan kegiatan. Kader Desa Cilayung tidak tampak keberatan. Keadaan ini mungkin berkaitan dengan tugas mereka sebagai penyuluh sehingga pemisahan kegiatan itu akan berakibat pada penambahan penyelenggaraan kegiatan penyuluhan itu. Para kader Desa Cipacing siap melakukan penyuluhan yang terkait pengendalian PTM, tetapi ingin lebih dahulu mendapat pelatihan untuk setiap materi, sedangkan kader Desa Cilayung merasa tidak sanggup memberikan penyuluhan.

"Kalau kami yang menyuluh, mungkin tidak akan didengar. Kalau dokter atau bidan atau mahasiswa yang memberikan penyuluhan, masyarakat pasti mau datang, dan mau mendengarkan.”(B4)

Pernyataan dari Kepala Puskesmas Kecamatan Jatinangor, Kab. Sumedang didapatkan informasi bahwa beberapa posyandu sudah melaksanakan kegiatan posbindu. Akan tetapi, berbeda dengan posyandu, dalam pelaksanaan posbindu tidak ada pelayanan yang diberikan oleh tenaga kesehatan, kegiatan sepenuhnya dilakukan oleh kader. Baik kader maupun kelompok penderita menyadari bahwa kegiatan posyandu PTM akan berbeda dengan posyandu KIA. Dukungan yang saat ini dibutuhkan oleh kelompok sasaran adalah edukasi, skrining, serta dukungan antarpasien supaya mampu menjalankan pengobatan dengan teratur. Kegiatan yang diinginkan oleh kelompok sasaran di kedua desa adalah edukasi rutin yang menyenangkan dalam bentuk ceramah maupun kegiatan bersama.

"Masak bersama, Bu. Seperti waktu sama mahasiswa dulu itu. Inget. Katanya kalau masak itu garamnya dimasukkannya nanti kalau sudah dingin masakannya."(B7)

Edukasi yang selama ini didapat baik dari tenaga kesehatan atau dari pihak lain dirasa tidak rutin karena program pengendalian PTM masih relatif baru ${ }^{1}$ sehingga mudah terlupakan. Buku atau selebaran tidak cukup hanya diberikan, tetapi juga perlu dijelaskan. Berbagi pengalaman sesama penderita hipertensi cukup menarik perhatian kelompok sasaran di Desa Cipacing dan mereka setuju bila sesama pasien menjadi salah satu kader penyuluh.

Kegiatan olahraga bersama dirasakan kurang menarik. Di Desa Cipacing terdapat pelatih senam aerobik yang datang seminggu sekali, peserta diwajibkan membayar Rp1.000,00-Rp5.000,00 setiap kali datang. Tidak banyak informan yang ikut serta dengan berbagai alasan antara lain lebih suka berjalan kaki sendiri dengan tujuan yang jelas, misalnya ke pasar. Kelompok sasaran di Desa Cilayung tidak menganggap olahraga penting karena dalam kegiatan mereka seharihari sudah cukup banyak gerak, terutama karena medan di Desa Cilayung yang berbukit-bukit.

"Sudah cape, Bu. Dari rumah ke warung saja sudah naek turun, belum lagi kalau ikut ke sawah."(D2)

Telah diketahui bahwa $1 / 3$ penderita hipertensi tidak mengetahui bahwa dirinya mempunyai tekanan darah yang tinggi sehingga skrining sangat perlu dilakukan. ${ }^{9}$ Dua posyandu di Desa Cipacing sudah melaksanakan skrining tekanan darah dengan menggunakan tensimeter digital. Mereka melakukan pemeriksaan tekanan darah terhadap penduduk satu RT dalam satu hari dan dapat menjangkau hampir seluruh penduduk. Mereka menemukan cukup banyak orang yang tidak mengetahui bahwasanya tekanan darahnya tinggi, tetapi para kader belum tahu apa yang harus dilakukan jika menemukan kasus dengan tekanan darah yang tinggi. Posyandu lain belum melaksanakan skrining.

Kepatuhan berobat secara umum rendah pada informan di kedua desa. ${ }^{10}$ Masalah ketidaktahuan 
mengenai cara dan prinsip pengobatan hipertensi adalah masalah terbesar dan ditambah dengan besarnya biaya transportasi (20-30 ribu rupiah, pergi pulang) untuk dapat mengambil obat dari puskesmas. Kelompok sasaran sangat berharap bahwa obat itu dapat didistribusikan melalui posyandu.

"Seperti obat-obat untuk ibu hamil atau balita sakit, kan dibawa oleh bu bidan. Kalau misalnya harus mengganti ongkos bu bidan juga tidak apa-apa." $\left.\mathrm{C}_{5}\right)$

Penyimpanan dan pendistribusian obat keras mempunyai protokol khusus sehingga Kepala Puskesmas Kecamatan Jatinangor, Sumedang menyampaikan:

"Jika di posyandu PTM akan diberikan obat, harus ada dokter yang menegakkan diagnosa, harus ada tenaga kefarmasian yang mengelola obat. Saat ini tenaga yang tersedia di puskesmas sangat terbatas sehingga tidak mungkin mengirimkan beberapa tenaga sekaligus ke lokasi posyandu."

\section{Pembahasan}

Dari pelaksanaan diskusi secara umum tampak bahwa kader Desa Cipacing bersifat lebih aktif dan berani mengemukakan pendapat. Karakter ini tampaknya terbentuk karena mereka banyak bekerja di bidang jasa maka sering berhubungan dan terbiasa berkomunikasi dengan orang lain sehingga mempunyai kepercayaan diriyang cukup tinggi. ${ }^{11,12}$ Interaksi kader dengan penduduk yang diwakili oleh para informan penderita hipertensi tampak cair dan setara. Di pihak lain, kader Desa Cilayung terutama yang berusia muda tampak lebih pasif dan memerlukan dorongan untuk mengemukakan pendapatnya. Karakter ini sesuai dengan sifat dari masyarakat tradisional Cilayung yang sebagian besar petani. ${ }^{11,12}$ Kebersamaan di daerah pedesaan dan rasa hormat terhadap orang yang lebih tua tampak dominan sehingga meskipun peneliti telah menempatkan diri yang setara dengan mereka, sikap sungkan dari kader yang lebih muda sangat terasa. Para kader Desa Cilayung sebagian besar adalah ibu rumah tangga dan beberapa orang berjualan di rumahnya. Beberapa kader dapat berinteraksi dengan baik, tetapi sebagian lagi bersifat apatis.

Informan kelompok sasaran berasal dari Desa Cilayung semuanya perempuan karena laki-laki sedang bekerja di sawah atau pun bekerja di luar kota. Informan cukup antusias dalam diskusi serta banyak memberikan masukan. Beberapa informan tampaknya lebih pasif, tetapi dengan dorongan yang lebih kuat mereka dapat mengikuti diskusi itu dengan baik. Diskusi antarinforman di Desa Cipacing sangat hidup dan salah seorang informan yang mempunyai banyak pengalaman bersemangat berbagi informasi dengan informan lainnya.

Berdasar diskusi dengan kelompok sasaran, disimpulkan kendala utama dalam pengendalian tekanan darah adalah pengetahuan yang kurang mengenai prinsip pengendalian tekanan darah, misalnya obat-obatan yang harus dikonsumsi secara berkelanjutan dan pentingnya gaya hidup sehat. Dibanding dengan daerah lain di Indonesia, Jatinangor termasuk kecamatan yang cukup maju oleh karena semua desa di Kecamatan Jatinangor mempunyai status swakarsa atau swasembada. ${ }^{12}$ Walaupun demikian, untuk dapat menjangkau fasilitas kesehatan masih merupakan kendala yang penting. Biaya tranportasi dari tiap-tiap desa untuk dapat mencapai puskesmas bervariasi antara 20 ribu sampai 30 ribu rupiah dan ini cukup memberatkan masyarakat. Pelaksanaan posyandu PTM dianggap memudahkan mereka untuk mengontrol tekanan darahnya karena akan mudah dijangkau dan pemberian penyuluhan tentang gaya hidup sehat di posyandu akan lebih meningkatkan pengetahuan tentang pola makan yang baik dan olahraga.

Edukasi merupakan aspek yang paling utama untuk mengatasi kendala-kendala di atas, tetapi keadaan itu tidak dapat dilakukan di puskesmas karena pertemuan dokter dengan pasien sangat singkat, dengan demikian diperlukan fasilitas lain untuk penyuluhan.6,7 Secara umum tampaknya masyarakat sudah dapat merasakan kebutuhan terhadap pelayanan posyandu PTM, khususnya untuk pemeriksaan tekanan darah dan edukasi mengenai pengendalian tekanan darah.

Berdasar atas diskusi mengenai tempat dan waktu pelaksanaannya posyandu PTM dengan kelompok kader dan juga kelompok sasaran di Desa Cipacing terdapat jawaban yang seragam mengenai lokasi pelaksanaan posyandu PTM, yaitu lokasi yang sama dengan posyandu KIA. Hampir semua posyandu KIA di Cipacing sudah mempunyai tempat khusus. Sementara itu, dari diskusi dengan kelompok kader dan kelompok sasaran di Desa Cilayung yang sebagian besar posyandu KIA-nya belum mempunyai tempat khusus, alternatif tempat yang dapat digunakan 
adalah musala maupun madrasah dan mereka menyatakan bahwa ustaz setempat atau ketua RW akan mendukung penggunaan kedua tempat tersebut. Keinginan anggota masyarakat tentang waktu dan tempat pelaksanaan posyandu PTM berbeda di kedua desa. Hal ini perlu dibicarakan bersama oleh para pemegang peranan baik kader sebagai pelaksana, masyarakat sebagai pengguna, dan pimpinan masyarakat sebagai pengayom kegiatan ini. ${ }^{8}$

Kader maupun kelompok sasaran di Desa Cipacing yang lebih bersifat perkotaan sudah cukup siap dan percaya diri untuk menjalankan dan memanfaatkan posyandu PTM. Satu hal yang belum terjawab adalah penanganan terhadap kelompok pekerja terutama pekerja pabrik yang bekerja dalam sif. Kelompok ini belum terwakili dalam DKT yang telah dilaksanakan tersebut. Kader Cipacing bersepakat bahwa kemungkinan akan lebih efektif bilamana posyandu PTM juga diadakan di pabrik-pabrik tempat sebagian besar penduduk Cipacing bekerja. Di daerah dengan masyarakat lebih lama berada di tempat bekerja, model posyandu PTM di tempat bekerja dapat menjadi prioritas. ${ }^{8}$

Pelaksanaan posyandu PTM itu di daerah dengan masyarakat yang homogen seperti di Desa Cilayung lebih mudah karena penentuan waktu dan juga lokasi dapat disepakati dengan lebih baik. Desa-desa yang homogen seperti ini lebih banyak yang membutuhkan pelayanan di luar gedung karena desa seperti ini biasanya yang sulit dijangkau oleh para tenaga kesehatan serta masyarakatnya sulit menjangkau sarana kesehatan. Dengan masalah tingkat pendidikan yang lebih rendah dan akses terhadap informasi yang terbatas maka daerah pedesaan merupakan sasaran yang akan mendapatkan manfaat lebih besar daripada posyandu PTM ini. ${ }^{13}$ Mengingat perbedaan kesiapan antara kedua desa tersebut kebijakan mengenai penyelenggaraan posyandu PTM tampaknya tidak dapat digeneralisasi dan harus disesuaikan dengan kondisi daerah dan masyarakatnya.

Berdasarkan atas wawancara dengan Kepala Puskesmas Kecamatan Jatinangor, Kabupaten Sumedang didapatkan informasi bahwa waktu ini puskesmas sudah melaksanakan program pengendalian penyakit kronis (prolanis) untuk pasien yang sudah terdaftar di puskesmas sebagai penderita penyakit kronis. Kegiatan dilaksanakan di kantor kecamatan, yaitu berupa penyuluhan dan senam setiap bulan, tetapi pemanfaatannya masih termasuk yang rendah. Pemanfaatan yang rendah terutama disebabkan oleh masalah biaya transportasi. Kesulitan akses dan transportasi memperlihatkan bahwa posyandu PTM akan sulit dilaksanakan dalam tingkat kecamatan ataupun desa seperti halnya prolanis ataupun posbindu. Posyandu PTM di sebuah RW akan lebih optimal terutama apabila posbindu/posyandu yang akan dibangun dibatasi pada pencegahan hipertensi dan komplikasinya. ${ }^{8}$

Kegiatan yang dapat dilakukan di posyandu PTM antara lain skrining tekanan darah dan faktor risiko lainnya, pemeriksaan tekanan darah pada para penderita hipertensi, penyuluhan pola hidup sehat, dan penggunaan obat antihipertensi. Seperti telah dikemukakan di atas, penyuluhan yang bersifat interaktif sangat diharapkan oleh kelompok sasaran, akan tetapi kegiatan olahraga kurang diminati. Minat berolahraga bersama yang rendah sebagai bagian dari kegiatan di posyandu PTM mungkin terkait dengan waktu pelaksanaan posyandu yang hanya sekali per bulan, sementara berolahraga harus dilakukan minimal 3 (tiga) kali dalam seminggu. ${ }^{8}$ Kegiatan olahraga bersama tampaknya tidak perlu menjadi prioritas, yang lebih penting adalah upaya untuk meningkatkan kesadaran dan juga pengetahuan masyarakat mengenai pentingnya aktivitas fisik yang cukup.

Dalam pelaksanaan skrining, Desa Cipacing mempunyai kepadatan penduduk yang lebih tinggi daripada Desa Cilayung sehingga jumlah penduduk yang harus diperiksa lebih banyak. ${ }^{12}$ Tantangan di Desa Cilayung adalah lokasi rumah penduduk yang tersebar sehingga memerlukan upaya yang lebih keras. ${ }^{12}$ Hasil skrining dapat dicatat dan dapat menjadi database yang baik bila dilakukan secara terintegrasi, tetapi sistem pelaporan ini memerlukan persiapan yang baik supaya tidak memberatkan kader dan hasilnya dapat dipergunakan oleh pemegang kebijakan untuk dapat menyusun program. Kementerian Kesehatan sudah menyusun laman untuk sistem pelaporan data pasien secara daring. Sarana ini dapat digunakan, tetapi memerlukan pelatihan lebih lanjut dan dukungan teknologi yang cukup tinggi. ${ }^{8}$

Keinginan para informan untuk mendapatkan obat di posyandu masih terkendala berbagai aturan keamanan tentang dispensing obat. Obat hipertensi merupakan obat keras yang harus diberikan atas resep dokter dan diserahkan oleh tenaga kefarmasian. Upaya mendekatkan fasilitas dispensing obat dan penjajakan kemungkinan pendirian posyandu PTM di tempat kerja masih 
memerlukan kajian yang mendalam. Meskipun demikian, sesuai dengan protokol pengendalian tekanan darah yang telah disepakati di seluruh dunia, obat bukan faktor yang terpenting dalam pengendalian tekanan darah. Gaya hidup sehat yang perlu ditingkatkan sebelum penggunaan obat hipertensi..$^{14,15}$ Dengan demikian, masalah keterbatasan distribusi obat-obatan yang saat ini belum dapat diatasi bukan menjadi halangan pelaksanaan posyandu PTM. Posyandu PTM dapat mengambil peranan skrining serta edukasi pencegahan PTM itu dan tetap dapat berperan dalam menurunkan angka kesakitan serta angka kematian akibat hipertensi dan PTM lainnya.

Sejauh ini, hanya terdapat dua posyandu di desa masing-masing yang sudah melaksanakan kegiatan untuk kelompok lanjut usia pada saat pelaksanaan posyandu KIA, tetapi kegiatannya masih terbatas pada pemeriksaan tekanan darah saja. Beberapa tenaga di puskesmas dan satu orang kader dari tiap-tiap desa telah mendapat pelatihan posbindu yang diselenggarakan Dinas Kesehatan Sumedang, tetapi belum dilakukan pelatihan terhadap kader lainnya. Perlu dilakukan koordinasi dengan pihak Dinas Kesehatan agar pelatihan kader posbindu/posyandu PTM dapat dilaksanakan.

Berdasarkan diskusi dengan kelompok kader didapatkan informasi bahwa peralatan untuk pelaksanaan posyandu PTM itu belum lengkap. Seluruh posyandu binaan sudah mempunyai tensimeter digital yang didapat dari tim peneliti. Pengukur tinggi badan dan juga meteran untuk mengukur lingkar perut dan lingkar kepala bayi dimiliki oleh sebagian posyandu. Alat lain yang dibutuhkan seperti timbangan dan glukometer serta kartu semacam KMS untuk balita belum ada. Dukungan dari masyarakat terutama untuk pelaksanaan rutin di posyandu belum dirasakan cukup. Satu posyandu KIA di Desa Cipacing telah mendapat bantuan dana konsumsi dari rumah makan yang berada di dekatnya. Pengalaman ini bisa menjadi contoh untuk peningkatan peran serta masyarakat khususnya pihak swasta.

\section{Simpulan}

Dari uraian di atas dapat disimpulkan bahwa kelompok sasaran sudah merasakan kebutuhan terhadap upaya peningkatan kemampuan diri mereka dalam pengendalian tekanan darah dan PTM lainnya. Kelompok sasaran di kedua desa siap memanfaatkan posyandu PTM. Dari pihak kader, beberapa keadaan masih menjadi kendala terutama kemampuan kader dalam memberikan penyuluhan dan ketersediaan alat.

\section{Ucapan Terima Kasih}

Ucapan terima kasih kepada Rektor Universitas Padjadjaran yang sudah mendanai penelitian ini melalui skema hibah Academic Leadership Grant tahun 2016-2017. Payung penelitian Pusat Studi Kesehatan dan Kebugaran Komunitas, Fakultas Kedokteran, Universitas Padjadjaran dengan judul 'Pencegahan Primer dan Sekunder terhadap Hipertensi pada Masyarakat Jatinangor'.

\section{Daftar Pustaka}

1. World Health Organization (WHO). A global brief on hypertension: silent killer, global public health crisis. Geneva: WHO Press; 2013.

2. World Health Organization (WHO). Health in 2015: from MDGs, millennium development goals to SDGs, sustainable development goals. Geneva: WHO Press; 2015.

3. Sabaté E, penyunting. Adherence to longterm therapies: evidence for action. Geneva: WHO; 2003.

4. Hotz S, Kaptein AA, Pruitt S, Sanchez Sosa J, Willey C. Defining adherence. Dalam: Sabaté E, penyunting. Adherence to longterm therapies: evidence for action. Geneva: WHO; 2003. hlm. 3-5.

5. Mendis S, Salas M. Hypertension. Dalam: Sabate E, penyunting. Adherence to longterm therapies: evidence for action. Geneva: WHO; 2003. hlm. 107-14.

6. Hidayah KAN, Sofiatin Y, Sitorus TDR, Roesli RMA. Management of hypertension in Puskesmas Jatinangor (unpublished). Bandung: FK Unpad; 2017..

7. Putri HR, Sofiatin Y, Roesli RMA. Gambaran penangkapan edukasi yang diberikan kepada pasien hipertensi di ruang konsultasi Puskesmas Jatinangor. JSK. 2017;2(3):14955.

8. Direktorat Pengendalian Penyakit Tidak Menular, Kementerian Kesehatan Republik Indonesia (Kemenkes RI). Petunjuk teknis pos pembinaan terpadu penyakit tidak menular (posbindu PTM). Jakarta: Kemenkes RI; 2012.

9. Hamzah NKA, Roesli RMA, Sofiatin Y, Sukandar H. Awareness, treatment and control of hypertension in Jatinangor sub- 
district between March-November 2014. J Hypertens. 2015;33:e34-5.

10. Putra MRD, Sofiatin Y, Hidayat EM, Sukandar H, Roesli RMA. Correlation between the correct use of drug and the achievement of blood pressure control. $\mathrm{J}$ Hypertens. 2015;33:e35.

11. Mondal P. Rural-urban differences: demographic and socio-cultural characteristics [diunduh 2 Agustus 2017]. Tersedia dari: http://www.yourarticlelibrary. com/difference/rural-urban-differencesdemographic-and-socio-culturalcharacteristics/39322.

12. Badan Pusat Statistik Kabupaten Sumedang.
Jatinangor dalam angka. Sumedang: Badan Pusat Statistik Kabupaten Sumedang; 2016.

13. Undang-Undang Republik Indonesia Nomor 26 Tahun 2007 tentang Penataan Ruang.

14. Chobanian AV, Bakris GL, Black HR, Cushman WC, Green LA, Izzo JL Jr, dkk. The seventh report of the Joint National Committee on prevention, detection, evaluation, and treatment of high blood pressure. Bethesda: US Department of Health and Human Services; 2003.

15. Indonesian Society of Hypertension (InaSH). Konsensus InaSH. ABC hipertensi: diagnosis dan tata laksana hipertensi. Jakarta: InaSH; 2015 . 